\title{
Leading by example
}

\section{The primary safeguard against scientific misconduct is the example set every day by thousands of senior researchers in the laboratory.}

- verybody likes a good scandal, and there is nothing like a fresh

- allegation of research misconduct to set tongues wagging in the scientific community and outside it.

There is broad agreement within the community on two main points regarding outright scientific fraud: it is rare, and it is serious. This unanimity frays at the marginal territory lying just beyond falsification and fabrication of data, however, where 'misconduct' may involve hogging the limelight for one paper too many, or tardy record-keeping at the laboratory bench. But even here, there is a reasonable consensus that scientists in every nation and every discipline will do the best for both themselves and their work by keeping all forms of substandard conduct to a minimum.

It has sometimes been argued that this is so because the credibility of the scientific enterprise is on the line. But if the truth be told, the smattering of egregious misconduct cases that have attracted widespread attention - the most recent being that of South Korea's Woo Suk Hwang - have made little ill impression on the generally favourable public attitude to science as a whole.

It is in fact the reliability of science - or to be more specific, that of the scientific record in the literature - that is the principal victim of scientific misconduct. No aircraft are going to fall out of the skybecause somebody fudged a graph in a materials-science journal. Rather, the problem is the time wasted by other scientists chasing up minor and not-so-minor infractions in pursuit of their own research.

A range of tools are available to help minimize research misconduct (see page 240). The most obvious are the systems of investigation and sanction that have been established in many nations. Rather less obvious, but perhaps just as useful, are the methods being developed to secure a scientific environment that is conducive to the highest standards of research conduct.

The thorough and fair investigation of misconduct allegations is a necessary activity that is fraught with difficulty, and likely to remain so. In the United States, the Office of Research Integrity at the health department and the Inspector General's office at the National
Science Foundation have between them overseen such investigations at universities for more than a decade now. But every investigation is a new and testing experience for the institution involved.

Parallel developments have occurred in Europe, especially in Germany, where the creation of an ombudsman system at the DFG, Germany's main research agency, in 1999 has provided useful impetus for fair and thorough university-based investigations. Other nations, induding Britain, still lack a national mechanism responsible for this - leaving institutions to fend for themselves, with uncertain results.

A more aggressive approach is being taken in east Asia, where major universities have responded sharply to recent misconduct allegations, constituting a major improvement on their past reluctance to act. However, it is not at all dear that this approach will extend beyond high-profile cases that have already found their way into the public domain - or that adequate checks are in place to assure the rights of the accused.

Attention should certainly be paid to nurturing the right framework for investigation and to setting up appropriate sanctions in an effective, cross-institutional manner. But hell will freeze over before an investigatory system can be developed that is universally recognized as comprehensive and fair.

In the interim, the scientific community should continue to concentrate on developing an environment that is inherently consistent with minimizing scientific misconduct.

A respectable level of ethics training for all postgraduate students is an important element of this. It needs to be introduced at all research universities - alongside stricter rules on record-keeping, and arrangements for protecting whistleblowers, where this is missing at the national level.

But most important of all, as the first scientific studies of the factors behind good conduct confirm, is the example set by senior researchers themselves. It is here in the laboratory - not in the law courts or the offices of a university administrator - that the trajectory of research conduct for the twenty-first century is being set.

\section{The database revolution}

\section{Funding agencies face conflicting challenges in supporting the databases essential tomodern biology.}

\footnotetext{
n molecular biology and genetics, high-throughput data gathering has progressed in a short time from a novel strategy of the few to a standard approach of the many.
}

Much of these data are not collected in a way that guarantees their accessibility to other researchers for future analysis. The best databases, however, are online agglomerations of raw and processed data, analytic tools and insights that have been collectively dubbed 'knowledge environments'.

Funding agencies are slowly adjusting their priorities to reflect the importance of consistent, assured support for some of these databases. The US National Institutes of Health (NIH), for example, has recognized that it must provide guidance for its research sections and grantees so as to maximize the return, in both knowledge and public health, on its investments in biomedical research.

Which strategies best support the collection, analysis and dissemination oflarge databases of related information? Do knowledge environments promote the aims of the funding agencies? At a meeting in Bethesda, Maryland, last month, it was clear that the NIH is 